\title{
Werner Michael Schwarz, Georg Spitaler et Elke Wikidal, Das Rote Wien 1919-1934. Ideen, Debatten, Praxis
}

Jean-Numa Ducange

\section{(2) OpenEdition}

Journals

Édition électronique

URL : https://journals.openedition.org/austriaca/1583

DOI : 10.4000/austriaca.1583

ISSN : 2729-0603

Éditeur

Presses universitaires de Rouen et du Havre

\section{Édition imprimée}

Date de publication : 1 juin 2020

Pagination : $270-273$

ISBN : 979-10-240-1492-0

ISSN : 0396-4590

Référence électronique

Jean-Numa Ducange, «Werner Michael Schwarz, Georg Spitaler et Elke Wikidal, Das Rote

Wien 1919-1934. Ideen, Debatten, Praxis », Austriaca [En ligne], 90 | 2020, mis en ligne le 01 juin 2020,

consulté le 12 octobre 2022. URL : http://journals.openedition.org/austriaca/1583 ; DOI : https:// doi.org/10.4000/austriaca.1583

Ce document a été généré automatiquement le 12 octobre 2022.

Tous droits réservés 


\title{
Werner Michael Schwarz, Georg Spitaler et Elke Wikidal, Das Rote Wien 1919-1934. Ideen, Debatten, Praxis
}

\author{
Jean-Numa Ducange
}

\section{RÉFÉRENCE}

Werner Michael Schwarz, Georg Spitaler et Elke Wikidal (dir.), Das Rote Wien 1919-1934.

Ideen, Debatten, Praxis, Bâle, Birkhäuser, 2019, 470 p., ISBN : 978-3-0356-1957-7.

1 Cet ouvrage, qui accompagne l'exposition récemment présentée à Vienne sur « Das Rote Wien 1919-1934» (à l'automne 2019), regroupe un important nombre de contributions sur les multiples aspects de l'expérience du pouvoir social-démocrate dans la capitale autrichienne entre-deux-guerres. L'ensemble rassemble des contributions de haut niveau, souvent dotées de multiples références, permettant d'offrir un panorama très complet des débats et pratiques à Vienne pendant cette période. L'une des grandes qualités de l'ouvrage est qu'il s'adresse aussi bien à des personnes ne connaissant guère le contexte qu'à des lecteurs plus spécialisés; les registres divers employés ici permettent de satisfaire la curiosité des uns comme des autres.

2 Wolfgang Maderthaner résume bien dans les premières pages la ligne qui prévaut tout au long de l'ouvrage: Vienne la Rouge fut une combinaison entre des mesures concrètes et immédiates et un projet d'utopie visant à dépasser le système politique et à changer radicalement les rapports sociaux : «Das Rote Wien ist ein radikales Projekt der Spätaufklärung. Es ist ein Projekt der Veralltäglichung der Utopie.» Un projet porté politiquement, mais soutenu au-delà des rangs socialistes avec des intellectuels et personnalités qui se trouvèrent pleinement impliqués dans l'aventure.

Un accent tout particulier, au cœur de l'exposition et qui se retrouve nettement ici, est le grand attachement à la Bildung, ou plus exactement à l'Arbeiterbildung. Déjà 
développée dans le Parti social-démocrate et à ses marges avant 1914, la «formation (ou éducation) ouvrière " prend tout sous sens avec le développement d'une politique culturelle ambitieuse visant à élever le niveau général du prolétariat, au moyen notamment de réformes scolaires. Un autre volet très détaillé concerne l'hygiène et la santé, tout particulièrement la lutte contre la mortalité et les maladies terrifiantes (notamment la tuberculose) qui touchaient les populations au lendemain de la guerre. Accompagnant cette dimension éducative et médicale, l'aspect éthique et moral est également souligné, faisant écho à une spécificité de l'austro-marxisme d'avant-guerre, qui avait entrepris une réappropriation de l'héritage kantien contre les tendances les plus orthodoxes de la Deuxième Internationale. Dans le même ordre d'idée, le fort encadrement de nombreuses initiatives par le Parti social-démocrate, s'il est resitué dans le contexte plus global de la croissance des partis de masses, est également rapproché de la structuration traditionnelle de l'Église catholique, filiation qu'il est impossible de minimiser dans le cas autrichien, même si l'anticléricalisme socialdémocrate était également une réalité tangible jusqu'aux années 1930.

Il paraît difficile d'énumérer tous les thèmes abordés ici ; on relèvera que, malgré la tendance à privilégier les aspects culturels et éducatifs, les dimensions politicoéconomiques ne sont pas oubliées. La politique fiscale (notamment à propos des Luxussteuern qui contribuèrent à polariser nettement les camps politiques dans les années 1920), en lien avec les amples projets de construction de logement, fait par exemple l'objet d'une attention spécifique. De même à propos de la psychanalyse un résumé précieux est proposé, et nous pourrions encore citer, sans exclusive, le sport ouvrier, le cinéma ou encore la musique (la célébration du centenaire de la mort de Beethoven en 1927, étudié spécifiquement, étant un exemple significatif et évoqué dans le détail).

D'autres contributions reviennent sur des aspects plus particuliers, en lien avec des sujets particulièrement prisés par l'historiographie actuelle. On peut citer à ce propos (à travers la publication d'Afrika singt en 1927) l'attention accordée à la pénétration de la culture afro-américaine à Vienne et la fascination qu'elle suscite. Plus largement, même s'il ne faut pas exagérer cette dimension - et qu'il est toujours difficile d'en apprécier la juste mesure chez les habitants ou même dans le milieu social-démocrate qui regroupait alors, rien qu'à Vienne, des centaines de milliers de membres -, l'ancrage international de l'expérience fut assurément un des aspects parmi les plus intéressants de ce qu'entreprit la social-démocratie de l'époque. Un exemple significatif, bien présenté ici, est le cas du quartier de Quarry Hill à Leeds en GrandeBretagne. Si des particularités proprement autrichiennes (au moins spécifiques au monde germanophone) singularisent la gestion municipale (en tout premier lieu la question de l'éducation/Bildung), le «rouge » de la Vienne des années 1920 entendait aussi renvoyer à une forme d'exemplarité internationale, voire développer une nouvelle forme d'universalisme. Ce n'est pas là l'essentiel ni le cœur de la plupart des contributions, ce que l'on pourra regretter d'ailleurs, tant la Vienne de l'époque suscita l'admiration (notamment dans plusieurs partis socialistes influents), mais il en est tout de même suffisamment question pour que cet aspect essentiel ne soit pas oublié. Cette dimension universelle fut particulièrement attaquée par ses adversaires, systématiquement rapprochée du "cosmopolitisme» juif, autorisant toute une propagande contre la social-démocratie présentant Vienne la Rouge comme une " création juive ». 
6 À noter qu'un vaste éventail de sources est proposé ici. Illustrations, affiches de propagande, photographies d'époque, témoignages des descendants des acteurs, etc. Rien ne manque à l'appel. Et en ouverture et conclusion, des retranscriptions de débats oraux d'historiens, journalistes et politiques sont proposées, concourant à la dynamique de l'ensemble. On y évoque par exemple la place des politiques d'entredeux-guerres dans la mémoire collective, jusqu'aux revendications, quelques décennies plus tard, du «droit à la ville ", qui n'ont rien perdu de leur force depuis. Sur ce point, la question du logement social occupe une place décisive, Vienne étant perçue assurément comme précurseur. Malgré cela, la « Rouge » demeure assez peu présente dans la mémoire collective et reste marginale dans le tourisme de la capitale, alors même que l'expérience a profondément marqué l'architecture de la ville au vingtième siècle, avec des continuités urbanistiques assumées par les sociaux-démocrates gérant de nouveau la ville après 1945, et ce au moins jusqu'aux années 1970.

7 Tout au plus pourra-t-on reprocher à l'ensemble d'être parfois un peu éclaté, et relativement peu critique à l'égard de la politique globale menée au cours de ces années par la social-démocratie. Certes ici et là sont suggérées les raisons de cet effondrement brutal en 1934 (les filiations de la Bildung avec la culture "deutsch-national », ou encore les formes d'inertie liées à un parti bureaucratisé aux effectifs pléthoriques), mais sans que le problème ne soit traité en tant que tel. Certaines intuitions auraient ainsi mérité de plus larges développements, comme le rapprochement entre la conception de la culture prônée par Otto Bauer avec celle avancée par Antonio Gramsci sur la dimension essentielle du combat culturel pour la politique sociale-démocrate. 